\title{
¿Qué imagen construyen los y las adolescentes sobre la vejez? Esencias y desafíos para una nueva cultura gerontológica
}

\section{What Image Do Teenagers Have of Old Age? Essences and Challenges for a New Gerontological Culture}

\author{
Ana María Cabrera Marsden \\ Universidad de La Habana \\ Cuba \\ anamaria@psico.uh.cu \\ Ana Hernández Martín. \\ Universidad de La Habana \\ Cuba \\ ana@psico.uh.cu
}

\section{Resumen}

La población cubana envejece a ritmos acelerados; para el año 2025, Cuba será uno de los países más envejecidos de América Latina. Promover acciones que, desde diferentes ámbitos de socialización, contribuyan a resignificar el papel de las personas adultas mayores en este contexto, permitirá asumir la edad desde una visión más positiva, participativa, saludable y exitosa. Las y los adolescentes cubanos crecen en un entorno que, cada vez con más frecuencia, aboga por patrones hegemónicos, androcéntricos y con marcadas incidencias en el valor de lo juvenil como lo verdaderamente importante. Los medios de comunicación masiva, la familia, la escuela y el barrio muchas veces promueven un tipo de vejez que acentúa la dimensión más negativa del asunto: deterioro, invalidez física y mental, dependencia, pérdidas de roles sociales, depresión, pasividad. Todos estos elementos se entrecruzan en 
la aprehensión de una cultura que aboga por una mirada paternalista y desde la carencia al llegar a la tercera edad. Una mirada a estos agentes de socialización en la adolescencia nos permite develar la presencia de valores negativos asociados a la vejez y al envejecimiento, los cuales dificultan una construcción positiva de la edad. Comienzan, sin embargo, a emerger algunas pautas en este contexto que permiten ir reconstruyendo esa cultura gerontológica. El presente trabajo devela algunos elementos de los diferentes agentes de socialización que dificultan la construcción de esa nueva cultura gerontológica desde edades tempranas y apunta hacia aquellos que, aun cuando son insuficientes, abogan por una construcción diferente del imaginario social sobre la tercera edad.

Palabras clave: Cuba, vejez, agentes de socialización, cultura gerontológica.

\begin{abstract}
Cuban population is rapidly aging. By 2025, Cuba will be one of the most aged countries in Latin America. Promoting actions, from different fields of socialization, in order to contribute to re-signify older people role in this context, will lead to assume age from a more positive, healthy and successful perspective. Cuban teenagers grow up in an environment advocating, more and more frequently, for patterns that are hegemonic, androcentric, and with noticeable incidences on the value of youth as truly important. The mass media, family, school and neighborhood often promote a type of old age that accentuates the most negative dimension of the issue: deterioration, physical and mental disability, dependency, loss of social roles, depression, and passivity. These are all elements that intertwine in the apprehension of a culture that advocates for a paternalistic view from the perspective of a person in need when reaching the old age. A look at these agents of socialization in adolescence allows us to reveal the presence of negative values associated with aging and old age which hinder a positive construction of age. However, patterns allowing the construction of that gerontological culture started to emerge in this context. This paper reveals some elements of the different agents of socialization that make difficult the construction of this new gerontological culture from the earliest ages, and also points to other elements that, although insufficient, advocate for a different construction of the social imaginary of the old age.
\end{abstract}

Keywords: Cuba, old age, agents of socialization, gerontological culture. 


\section{A modo de introducción}

Cuba asiste a un proceso demográfico sin antecedentes en la historia. Con una población mayor de sesenta años que asciende a las 204139211 personas (lo que representa el 18,7\% de la población) (ONEI, 2012), nuestro país se ubica entre los más longevos de América Latina y el Caribe. Datos recientes ofrecidos por la Oficina Nacional de Estadística e Información afirman un crecimiento poblacional en los últimos cuatro años. Hoy Cuba posee un 19\% de su población envejecida. Esta situación comienza a tener un impacto perceptible en los diversos ámbitos de la vida social.

Deviene en un proceso que reclama la atención para la formulación de políticas públicas, científicas, mediáticas, educativas y sanitarias que abarca diferentes sectores y grupos etarios y no solo a las personas de la tercera edad. Ello encuentra cabida en el lineamiento 144 de la Política Económica y Social del Partido y la Revolución (2011) que tiene como objetivo "brindar particular atención al estudio e implementación de estrategias en todos los sectores de la sociedad para enfrentar los elevados niveles de envejecimiento de la población". La lógica de este proyecto de país en la organización y desarrollo de la sociedad involucra a diversos actores sociales encargados de promover una cultura gerontológica que incluya aprender a envejecer y a convivir en una sociedad envejecida desde edades tempranas del ciclo vital. En este sentido, la educación se erige como pilar fundamental para favorecer espacios de reconocimiento, inclusión y aceptación de la persona mayor.

En los espacios de debate científico sobre el tema se afirma que Cuba no está preparada para asumir los retos que impone una población envejecida (Alfonso, 2014; Orosa, 2014a). Los medios de comunicación masiva, la familia, la escuela y el barrio muchas veces promueven un tipo de vejez que acentúa la dimensión más negativa del asunto: deterioro, invalidez física y mental, dependencia, pérdidas de roles sociales, depresión, pasividad. Todos estos elementos se entrecruzan en la aprehensión de una cultura que aboga por una mirada paternalista y desde la carencia, al llegar a la tercera edad.

En este contexto, ¿qué imagen construyen los grupos adolescentes cubanos sobre la vejez?, ¿qué piensan, sienten, creen sobre esta etapa?, ¿qué modelos guían su construcción sobre la vejez?, ¿cuál es la influencia de los agentes de socialización en la construcción de su imaginario sobre la vejez y la suya propia? 
La propuesta que presentamos intenta aproximarse a una caracterización de los diferentes agentes de socialización que potencian, o no, una aprehensión de la nueva cultura gerontológica. Esta cultura la entendemos como un conjunto de valores, ideas, creencias y actitudes favorables hacia el proceso de envejecimiento y la vejez.

\section{Realidades que hacen pertinente una nueva cultura gerontológica}

\section{Desde la familia}

Las nuevas dinámicas demográficas han influido en la reconfiguración de los espacios familiares. La presencia cada vez más frecuente de núcleos familiares en los que figura al menos una persona adulta mayor ha colocado la mirada en un fenómeno que involucra espacios de articulación-desarticulación entre varias generaciones, especialmente entre adolescentes y personas adultas mayores, en los que, por las características propias de la adolescencia, comienzan a emerger conflictos con las figuras adultas. Este conflicto puede agravarse si se entremezcla con brechas del orden intergeneracional; pues los valores, normas de conducta, modos de hacer y ser y, en general, las concepciones del mundo presentes en estas mismas se constituyen como antagonismos. Los patrones de relación establecidos entre estas generaciones marcan distancias y diferencias de perspectivas que las colocan en situación de confrontación sobre cuestiones de la vida cotidiana. Estos conflictos van desde lo familiar hasta lo laboral y comunitario, lo que deviene en contradicciones intergeneracionales que frenan los procesos participativos, de autorrealización, de producción, de inclusión, etc.

Las generaciones adolescentes suelen ser más críticas en sus valoraciones sobre las personas adultas que les rodean, quienes dejan de ser las figuras sagradas de etapas anteriores. "El carácter dicotómico del pensamiento y la ausencia de una consolidación de algunas formaciones motivacionales, contribuyen a que esta valoración sea poco reflexiva y rígida" (Domínguez, 2006, p. 215 ).

La causa de este conflicto radica en la divergencia de opiniones entre adolescentes y mayores en cuanto a los deberes y derechos de los primeros. (Domínguez, L., 2006).

Aunque en el caso del vínculo relacional que establecen los sujetos adolescentes con sus abuelos o abuelas se torna a veces conflictivo, este responde más a la presencia del conflicto o brecha generacional que al propio conflicto adultoadolescente. Según Laura Domínguez (2006), "la sucesión entre generaciones 
es siempre selectiva: unos conocimientos, normas y valores se asimilan y se trasmiten a la nueva generación, mientras otros que no se corresponden con las nuevas circunstancias son rechazados o transformados" (p. 217). Esta situación de conflicto se presenta en disímiles espacios en los que convergen ambas generaciones: escolares, familiares, barriales y sociales. Abarcan diferentes escenas de la vida cotidiana como los valores cívicos y morales, el empleo del tiempo libre y las actividades de ocio, intereses culturales, espacios de consumo cultural y preferencias culturales, uso de la moda, etc.

A este hecho que acontece con sus peculiaridades en cada contexto y época social habría que añadirle, en la actualidad, la presencia cada vez más rápida de cambios sociales, la tecnologización acelerada en todos los espacios de la vida cotidiana, la trasmisión masiva por los medios de comunicación de valores e informaciones que no favorecen modelos educativos consecuentes con elementos de convivencia intergeneracional y el aislamiento cada vez más frecuente entre miembros de la familia que conviven en un mismo hogar.

Estas condiciones aceleran un distanciamiento entre las generaciones que no favorecen espacios de inclusión y con-vivencia generacional efectivos en los que ambos grupos etarios puedan poner en común lo que pueden hacer juntos en pos del desarrollo psicosocial de unos y otros. Los ritmos acelerados en los que se vive hoy potencia un crecimiento de adolescentes en el que la figura de la persona mayor deja de ser el reservorio de sabiduría para convertirse en depositaria de saberes susceptibles de ser aprendidos en la interacción, muchas veces, con sus nietos y nietas adolescentes.

Es también un reto para las actuales generaciones de mayores aprender a convivir en espacios multigeneracionales. Son quizás estas generaciones las que tienen un mayor peso en la re-configuración de la mirada adolescente hacia las personas mayores. En la medida en la que estos espacios se conviertan en escenarios que favorezcan una comunicación efectiva para ambas generaciones, se posibilitará un mayor acercamiento entre ambos grupos etarios y, como consecuencia, un mayor conocimiento y co-aceptación de las características propias del período del desarrollo por el que atraviesan. 
La efectividad de las relaciones interpersonales y la solución constructiva de los conflictos que puedan emerger en la interacción de las diferentes generaciones, funcionan necesariamente como potenciadores de crecimiento personológico. (Pérez, p. 278)

Esta convivencia multigeneracional también ha incidido en una nueva forma de mirar la vejez desde la subjetividad adolescente. Al vivir más años, la persona adulta mayor que convive con generaciones más jóvenes se convierte en referente directo desde el cual estos construyen su comprensión de la vejez y el envejecimiento.

La inserción de las autoras en contextos de trabajo grupal con adolescentes ha develado la emergencia de una preocupación tácita de este grupo poblacional sobre las cuestiones relacionadas con el envejecimiento poblacional: "cómo aprender a cuidar a mi abuelita", "hacer un video sobre lo que pasa cuando uno es viejo", “¿qué pasa cuando uno es ya mayor?”, "tengo miedo a que le pase algo a mi abuela; cómo hago para ayudarla".

Si bien la sociedad no está preparada para asumir los retos de una población envejecida, menos lo está la familia para preparar a sus miembros más pequeños de casa a asumir "naturalmente" la entrada de sus abuelos y abuelas a la tercera edad. Es frecuente encontrar espacios familiares en los que el cuidado de la persona adulta mayor se convierte en crisis familiares que devienen en tensión y preocupación también para el adolescente, a quien, además se le involucra, muchas veces, en el cuidado de esa persona mayor. ¿Cómo ocurre este proceso? En ocasiones se ve el cuidado como una carga para la familia y más para el sujeto adolescente, quien tiene otras necesidades e intereses; desde la responsabilidad y otras desde el compromiso, también negativo, de retribuir al abuelo o abuela que se encargó del cuidado durante los primeros años de vida de ese infante. Esta situación, más allá de favorecer un espacio de comprensión positiva de la tercera edad, influye en la construcción de la vejez desde el deterioro, la enfermedad, la sobrecarga y la molestia.

Una mirada a la vejez desde las personas adolescentes con las que las autoras han trabajado permite develar, en algunos casos, la presencia de actitudes negativas y conductas de maltrato hacia la persona mayor que denotan una "desconexión" con la realidad que vive ese mayor: "ese viejo camina muy lento, me desespera", "yo no quiero llegar a esa edad (la vejez)...total para ser un estorbo", “... si todos los viejos son tremendos chismosos, andan en lo que no le importa". 
Sin embargo, comienzan a emerger otros contextos que pueden ser potenciadores para favorecer una mirada positiva de la edad: los nuevos referentes de familia, la construcción familiar desde la trasnacionalidad y la manera en la que se vive la llamada "abuelidad de nuevo tipo". Hoy asistimos a un proceso de reconfiguración de los paradigmas de asumir los roles de abuelos y abuelas. Cada vez es más frecuente encontrar a quienes prefieren aprender a serlo en esta época, a disfrutar la abuelidad y acompañar el proceso de desarrollo familiar, pero también preservar proyectos de vida propios, bien de pareja, de estudio o de contribución social (Orosa, T., 2001).

Desde esta mirada, encontramos adolescentes que comienzan a valorar la importancia de un aprendizaje durante toda la vida: "mi abuela comenzó a estudiar en la universidad y aprendió cosas que después me enseñaba a mí y a todos en la casa. Ya ella no estaba todo el día pendiente de lo que pasaba, empezó a tener otros planes", "me alegró saber que [mi abuela] sabía más que yo de computación y tenía una agilidad en el teclado perfecta que adquirió en el Joven Club de Computación"; a comprender la edad como un periodo etario del desarrollo: "llegar a la tercera edad es vivir otra etapa de la vida", "esa edad tiene sus cosas buenas y malas, como las demás", "tenemos que aprender que es otra etapa de la vida".

La familia constituye el vínculo de integración más importante y es la esfera que permanece presente en el desarrollo socio-psicológico del individuo a lo largo del ciclo vital. Las relaciones familiares ya sean entre una misma generación o intergeneracionales son fuentes de satisfacción de importantes necesidades en la jerarquía motivacional de las personas. Estas necesidades de integración, asociacionismo, afiliación, afecto, son importantes fuerzas movilizadoras de comportamientos para el logro y mantenimiento de su satisfacción. (Pérez, pp. 279-280)

Al igual que otros roles familiares también se encuentran influenciado por los cambios que la familia como institución transita en la actualidad; hoy resulta imposible reproducir patrones de abuelidad de otras épocas, no solo porque los nietos y nietas hayan cambiado sino porque también las personas mayores han cambiado.

En el contexto nacional se comienza a hablar denuevas tipologías de abuelidad. Arés (2013), al abordar los cambios de la familia en la actualidad, refiere la existencia de diferentes tipos de vivir el rol: síndrome de la abuela esclava sostenedora de 
tres generaciones, encargada de los quehaceres del hogar y del cuidado de nietos y nietas; los abuelos instantáneos cuando los hijos o hijas rehacen pareja y los primeros asumen la abuelidad de esos "nuevos nietos"; también hay abuelos y abuelas que aparecen en ocasiones especiales; abuelos mucha marcha, que tienen muchas actividades, que construyen nuevos proyectos de vida, que tienen una vida activa socialmente y se involucran en disímiles espacios de participación social y los abuelos y abuelas trasnacionales o cyberabuelos, que ejercen su rol desde la distancia fronteriza, lo mantienen desde la comunicación que posibilitan las nuevas tecnologías de la informática y las comunicaciones.

La existencia de una familia extensa tradicional, en la cual las figuras mayores (principalmente la masculina) se hallaban a cargo del control, dirección, coordinación y decisión en el hogar; ha dado paso mayoritariamente (excepto en algunas zonas rurales) a una familia igualmente extensa, donde el poder de decisión lo tiene el miembro (ya sea hombre o mujer) responsable del sostenimiento económico de la familia, de la cual se han independizado familias nucleares, según las posibilidades económicas. En esta nueva configuración familiar, las personas mayores han cedido su puesto directivo y se da lugar a una relación más igualitaria y menos rígidamente jerarquizada.

La presente generación adulta mayor se ha de adaptar a dos cambios fundamentales. En primer lugar, los eventos vitales propios del período como la jubilación, la abuelidad, la viudez, y la propia muerte, que se evidencian esencialmente en el espacio familiar. En segundo lugar, se deben adaptar a la evolución que ha tenido el estatus y la jerarquía de los mayores en la familia (Orosa, 2001). La evolución del significado de "ser adultos mayores" que aprendieron cuando aún no lo eran, es muy diferente y puede entrar en contradicción con algunas exigencias actuales de este rol.

Sin duda, es la familia un espacio importante desde donde los grupos adolescentes comienzan a construir ese imaginario sobre la vejez y el envejecimiento.

\section{Desde la escuela}

El espacio escolar constituye un importante ámbito desde donde debieran construirse los aprendizajes de la vida adolescente. Es, entre otras, la institución encargada de promover valores y actitudes positivas hacia la vejez y el envejecimiento. Sin embargo, la realidad educativa demuestra lo contrario. Es 
este ámbito uno de los más desfavorecedores para la promoción de una cultura gerontológica, en tanto encontramos:

- Ausencia o escaso tratamiento de temas gerontológicos en las diferentes asignaturas de las enseñanzas primaria, secundaria y preuniversitaria. Los programas de estudio no contemplan la inclusión de la mirada gerontológica en los diferentes escenarios de la vida cotidiana. Poco se habla de los cambios demográficos y de los retos que ello impone a la sociedad.

- La enseñanza va dirigida hacia el respeto por la persona mayor, no hacia la comprensión de la vejez como etapa de la vida y el aprender a envejecer. Si bien es importante educar a las generaciones más jóvenes hacia el cuidado, protección y respeto de las mayores, más importante es enseñarles a envejecer. Nuestros programas docentes deberían incluir temáticas relacionadas con los procesos demográficos y las regularidades de la vejez, en el entendido que debemos prepararnos para llegar a esa etapa de la vida desde una mirada activa, participativa y exitosa; eso solo es posible si aprendemos a envejecer desde paradigmas diferentes a los que dominan hoy en nuestras sociedades. Ello implica comprender que se envejece desde que se nace y que es un proceso natural para el cual las personas y la sociedad deben prepararse, fundamentalmente desmontando estigmas y prejuicios que denotan a la vejez como pérdida y deterioro.

- Poca preparación de docentes en temas gerontológicos. Justamente el poder ofrecerle al estudiantado aprendizajes acordes a una cultura gerontológica está atravesada por la preparación de sus docentes.

\section{Desde lo social - comunitario}

Si bien el espacio de lo barrial se erige como un área en la que comienza a entreverse una mirada hacia la vejez que aboga por una cultura gerontológica como la presencia de actitudes negativas y conductas de maltrato hacia la persona mayor, también encontramos otras acciones que favorecen un cambio en el imaginario social sobre la vejez. En ese sentido, es frecuente encontrar espacios para el intercambio intergeneracional; aulas o universidades de mayores que reconfiguran el lugar de la persona adulta mayor en la sociedad, al colocarla en el escenario educativo; una mayor visibilidad de personas adultas mayores en los contextos comunitarios como gestores medioambientalistas y socioculturalistas; así como la presencia, cada vez más frecuente, de individuos mayores en los 
espacios laborales del sector no estatal de la economía, lo que los posiciona desde una mirada emprendedora.

\section{Desde los medios de comunicación masiva}

Las generaciones adolescentes de la Cuba de hoy crecen en un entorno caracterizado por el desarrollo paulatino y vertiginoso de los medios de comunicación y las nuevas tecnologías. La participación, cada vez más frecuente, de los productos mediáticos en su vida nos convida a analizar cómo estos se insertan en la construcción conjunta de nuevas realidades.

Indagar y caracterizar las prácticas culturales de nuestra población, la relación de los grupos poblacionales con las ofertas culturales, las expectativas y motivaciones que condicionan estas prácticas, así como los usos que hacen de ellas, y las visiones sobre la vejez y el envejecimiento que se transmiten en los diferentes medios de comunicación constituyen problemáticas fundamentales para desarrollar acciones encaminadas a mejorar y transformar los imaginarios culturales en torno a estas temáticas.

Las particularidades en los estilos de vida de adolescentes, sistemas de motivos, jerarquización de necesidades, oportunidades culturales con las que cuentan desde su localización espacial y, con ello, los patrones culturales que se han venido conformando, nos obliga a pensar que todos estos procesos y muchos otros influyen en el consumo que adolescentes están haciendo de los medios de comunicación y que inciden directamente en la conformación de una imagen de la vejez que dista mucho de ser activa, exitosa, positiva.

Las revistas que suelen leer son de moda y entretenimiento (Hola, Vanidades, Cosmopolitan, Marca, etc.) con un cargado componente que aboga por una cultura del consumo y en el que se privilegia la presencia de lo juvenil como patrón de supremacía. En este tipo de revista priman los mecanismos de dominación cultural que estimulan un gusto estético universal y cambiante, en coherencia con el proceso de producción capitalista. La industria de la moda femenina oferta una imagen y preferencias, estatus social, relaciones interpersonales y el "buen gusto al vestir" que las adolescentes cubanas tratan de compartir con sus coetáneas amén de sus posibilidades económicas. Se vislumbra una preferencia por revistas internacionales en detrimento de las nacionales, en la mayoría de las cuales las personas adultas mayores no ocupan espacio. ¿Son acaso las personas 
de la tercera edad una población desprovista de gustos estéticos y beneficiaria de la moda?

El visionado televisivo se concentra en películas, novelas y musicales que, al igual que las revistas, son en su mayoría preferencias audiovisuales de producción extranjera que ofrecen contextos sociales distantes de nuestra realidad. Se aprecia una escasez de imágenes de la vejez en las producciones animadas y juveniles. En estas últimas, muchas veces se omite la presencia de la persona adulta mayor y cuando esta aparece lo hace desde la carencia, la enfermedad, necesitada de cuidados o desde la burla. Para los grupos más pequeños emerge "Chuncha" como un paradigma diferente de asumir la abuelidad y la vejez: desde el asociacionismo, la participación, la integración social.

La preferencia de géneros cinematográficos es, en este orden: comedias, ciencia ficción/fantástico y horror/suspenso, géneros en los que pocas veces se promueven valores sociales y humanistas, y en los que la figura de la persona adulta mayor, al igual que en la producción televisiva, aparece invisibilizada. Desde las producciones cinematográficas surgen vejeces desde el deterioro, la dependencia, la soledad, la enfermedad. Pocas producciones enfatizan en lo activo, participativo, productivo y positivo que también trae aparejada la vejez, como etapa del ciclo vital.

Las producciones mediáticas están presentando una imagen de la vejez que no contribuye a los procesos identitarios en la tercera edad, menos al reconocimiento, por parte de los grupos adolescentes, como una etapa portadora de pérdidas y ganancias y regularidades propias como periodo del desarrollo. Se realiza un tratamiento burlesco y peyorativo de la vejez, en el que se privilegia lo "productivo-joven"; se defienden a ultranza los atributos físicos de la juventud; el sujeto adulto mayor aparece en la mayoría de las ocasiones solo en su rol de abuelidad; lo que lo despoja de la asunción de otros roles sociales como hombre o mujer, como activista social; envejecimiento y vejez son abordados, por lo general, desde la geriatría; no hay una comprensión desde la gerontología. Son todos estos elementos que reniegan la vejez y el proceso de envejecimiento y que colocan los patrones de lo juvenil, masculino y occidental como los referentes desde los cuales se "construye" el mundo actual.

Gran parte de los elementos que hemos sintetizado en los diferentes ámbitos de socialización, sin bien no son los únicos, nos permiten dilucidar la presencia de 
referentes positivos y negativos para la construcción de un imaginario sobre la vejez. La mayoría de las veces son elementos que se entrecruzan en la aprehensión de una cultura que aboga por una mirada paternalista y desde la carencia al llegar a la tercera edad: invalidez física y mental, pérdidas de roles sociales, deterioro, pasividad/inactividad y depresión; elementos estos que atentan directamente con los significados construidos en torno al cuerpo y la relevancia social que le es atribuida a los viejos y las viejas.

Sin embargo, como hemos observado, comienzan a emerger una serie de elementos que contribuyen a la formación de otras comprensiones sobre la edad. Justamente nos encontramos en una transición cultural sobre los temas gerontológicos en los que se entremezclan unas y otras visiones. De ahí la importancia de seguir haciendo y construyendo nuevos espacios para que nuestras generaciones adolescentes puedan aprender la nueva cultura gerontológica por la que apostamos.

\section{A modo de conclusión: Retos que el contexto impone}

- Fomentar una cultura de inclusión, equidad y potenciación de los recursos personales, sociales y ciudadanos de la población que articule todos los sectores de la sociedad.

- Implementar acciones educativas con adolescentes que permitan desmontar mitos y estereotipos en torno al envejecimiento y la vejez, conocer las características sociopsicológicas de la etapa y de ahí la manera en la que nos relacionamos con las personas mayores constituye un primer paso para transformar la realidad de esos y esas adolescentes y compartir otras maneras de con-vivir con adultas y adultos mayores y ayudarles a construir su propia vejez desde paradigmas más positivos.

- Responder a las demandas mediáticas de adolescentes en combinación con contenidos educativos, pero siempre atractivos. Repensar la manera en la que se está enseñando a "ser viejo o vieja" a través de los mensajes mediáticos, la información que se transmite, cómo se hace y el lenguaje que se utiliza.

- Crear espacios de convergencia intergeneracional. Hemos observado, en los grupos de adolescentes con los que trabajamos, un desconocimiento sobre la vejez como etapa de la vida, así como poca preparación para aprender a envejecer e interactuar con personas adultas mayores en un contexto que se vislumbra cada vez más como una población envejecida. 
- Ello repara en la importancia de acometer acciones que, desde la educación, favorezcan procesos de sensibilización con la vejez y el envejecimiento; en tanto premisa necesaria para aprender nuevos paradigmas sobre la manera en la que las personas viven su propia vejez (Orosa, 2014b; Zamarrón, 2013; Zarebski, 2015). Ello enfatiza en la urgente necesidad de incorporar, en nuestros distintos niveles de enseñanza, programas educativos para la sensibilización con el envejecimiento y la vejez, a través de los cuales estos grupos etarios podrán "entender" y "atender" la vejez desde posiciones más reflexivas y críticas, y convertirse, a su vez, en agentes de transformación en sus espacios de articulación con otros sujetos adolescentes y familiares. Estas personas adolescentes luego podrán ser "adultos y adultas mayores de nuevo tipo".

\section{Referencias}

Alfonso, J. (2014). Envejecimiento poblacional. Actualidades. Conferencia ofrecida en el Balcón Latinoamericano. FLACSO.

Arés, P. (2013). Retos de la familia cubana. Curso presentado en los marcos del Evento Edumayores.

Oficina Nacional de Estadística e Información (2012). Censo de población y viviendas. Informe Final. Cuba.

Domínguez, L. (2003): El sistema de comunicación en las etapas de la adolescencia y la juventud: Relaciones con los adultos. En L. Domínguez (Comp.), Psicología y desarrollo: Adolescencia y juventud. Selección de lecturas (2006, 1era reimp., pp. 214-221). La Habana: Editorial Félix Varela.

Hitzig, J. (s. f.). Envejecer en el tercer milenio. En G. Zarebski y R. Knopoff (Comps.). Viejos nuevos. Nuevos viejos (pp. 127-132, 2001). Buenos Aires: Tekné.

Knopoff, R. (s. f.). Los viejos en el mundo de hoy. En G. Zarebski y R. Knopoff (Comps.). Viejos nuevos. Nuevos viejos (pp. 21-26). Buenos Aires: Tekné.

Lineamientos de la Política Económica y Social del Partido y la Revolución. (2011). VI Congreso del Partido Comunista de Cuba.

Orosa, T. (2001). La tercera edad y la familia: Una mirada desde el adulto mayor. 
La Habana: Editorial Felix Varela.

Orosa, T. (2014a). ¿Qué significa ser adulto mayor en la actualidad? (Conferencia ofrecida en el Balcón Latinoamericano). FLACSO. 14 de mayo de 2014.

Orosa, T. (2014b). La psicogerontología en Cuba. Experiencias y retos actuales. Artículo en Edición para su publicación.

Pérez, V., (s. f.). Las relaciones intergeneracionales en la actualidad: La generación de los adultos mayores. En T. Orosa (Coord.) Temas de psicogerontología (2014, pp. 267-292). La Habana: Editorial Félix Varela.

Zamarrón, M. (Mayo, 2013). Envejecimiento activo: Un reto individual y social. Sociedad y utopía. Revista de Ciencias Sociales, 41, 449-463. Recuperado de http://www.unav.edu/matrimonioyfamilia/observatorio/uploads/31218_Zamarron_SU2013_Envejecimiento.pdf 